\title{
Severe cutaneous and arthritic psoriasis in patient with Aids: a good outcome with therapy using etanercept
}

\author{
Psoríase cutânea e artropática grave em paciente com Aids: boa resposta tera- \\ pêutica com uso de terapia com etanercepte
}

\author{
Mônica Santos ${ }^{1}$ \\ Luciana Mendes ${ }^{2}$ \\ Carolina Talhari ${ }^{3}$
}

\author{
Renata Rabelo ${ }^{2}$ \\ Virginia Vilasboas ${ }^{2}$ \\ Sinésio Talhari ${ }^{4}$
}

\begin{abstract}
We report the case of a patient with cutaneous and arthropathic psoriasis for eight years, whose sudden increased severity of the clinical picture led to a diagnosis of AIDS, emphasizing the importance of the specialist in the diagnosis of systemic diseases. The appropriate therapeutic interventions, including antiretroviral therapy and the immunobiological agent etanercept, enabled rapid improvement of symptoms and quality of life of the patient, besides contributing to delay in immunodeficiency progression.

Keywords: Acquired immunodeficiency syndrome; Arthritis psoriatic; Psoriasis; Therapeutics

Resumo: Relata-se o caso de um paciente com psoríase cutânea e artropática há oito anos, cujo agravamento súbito do quadro clínico levou ao diagnóstico da Aids, ressaltando a importância do especialista no diagnóstico de doenças sistêmicas. A intervenção terapêutica apropriada, incluindo a terapia antirretroviral e agente imunobiológico - etanercepte - possibilitou a rápida melhora do quadro clínico e da qualidade de vida do paciente, além de contribuir para o retardo na progressão da imunodeficiência.

Palavras-chave: Artrite psoriásica; Psoríase; Síndrome de imunodeficiência adquirida; Terapêutica
\end{abstract}

\section{INTRODUCTION}

Psoriasis is a chronic inflammatory disease that affects from 2 to $3 \%$ of the worldwide population, frequently involving the skin and articulations. Its etiology is multifactorial, with participation of genetic, autoimmune and environmental factors. More recently the role of cells and inflammatory mediators in the pathogenesis of the disease was demonstrated and it is now defined as a systemic inflammatory affection of autoimmune nature ${ }^{1}$. The inflammatory symptom complex of psoriasis may be exacerbated by environmental factors, including viral infections, mainly HIV infection. ${ }^{2}$ Articular involvement may take place in 6 to $42 \%$ of patients with skin psoriasis, with variable spectra, from non-erosive to severe and debilitating arthritis. Such clinical pictures should be differentiat- ed from reactive arthritis, which is characterized by the triad polyarthritis, urethritis and conjunctivitis, together with the typical skin lesions. Studies also show that in patients with HIV/AIDS, articular involvement is usually more extensive and refractory to the customary therapy. ${ }^{3}$

This paper presents a case of cutaneous and arthropathic psoriasis, whose sudden clinical picture exacerbation led to AIDS diagnosis, highlighting the importance of the dermatologist in the diagnosis of systemic diseases. The appropriate therapeutic intervention, including antiretroviral therapy and the immunobiological agent etanercept, resulted in rapid improvement of the clinical picture and quality of life of the patient.

Received on 09.03.2011.

Approved by the Advisory Board and accepted for publication on 01.05.2011.

* Study carried out at Tropical Medicine Foundation of the Amazon (Fundação de Medicina Tropical do Amazonas - FMTAM) - Manaus (AM), Brazil.

Conflict of interest: None / Conflito de interesse: Nenbum

Financial funding: None / Suporte financeiro: Nenhum

MD, PhD in Tropical Medicine. Dermatologist at the Tropical Medicine Foundation of the Amazon (Fundação de Medicina Tropical do Amazonas- FMTAM) and Professor of dermatology at the State University of the Amazon (Universidade do Estado do Amazonas - Manaus (AM), Brazil.

MD, resident of dermatology at the Tropical Medicine Foundation of the Amazon (Fundação de Medicina Tropical do Amazonas- FMTAM) - Manaus (AM), Brazil.

MD, PhD in Tropical Medicine. Professor of dermatology at the State University of the Amazon (Universidade do Estado do Amazonas) and Nilton Lins University(Universidade Nilton Lins) - Manaus (AM), Brazil.

$\mathrm{MD}, \mathrm{PhD}$ in dermatology - Professor of dermatology at Nilton Lins University (Universidade Nilton Lins) - Manaus (AM), Brazil. 


\section{CASE REPORT}

Clinical Picture: A 32-year-old male patient, single, was diagnosed with cutaneous and arthropathic psoriasis in 2002. As the skin lesions regressed soon after the beginning of treatment, the patient was monitored only through rheumatology, using methotrexate (MTX), 15mg/week, since the diagnosis (cumulative doses of $5040 \mathrm{mg}$ ), with good clinical control of the disease. In June 2009, new skin lesions appeared, associated with marked recrudescence of the articular involvement and $10 \mathrm{~kg}$ weight loss. The onset of skin lesions was the motive for referral to dermatology. Dermatological examination: presence of erythematous-squamous plaques, some of them with crusts, predominantly in the inguinal, palmo-plantar regions and back of hands (Figure 1). Articular Examination: arthritis in the proximal and distal interphalangeal articulations of hands, metacarpophalangeal articulations, wrists and thigh-femoral articulations. At the initial examination, PASI (Psoriasis Area and Severity Index) score was 19 (Figure 2). Supplementary tests: positive serology for HIV, with a T CD $4+$ cell count of 217 cells $/ \mathrm{mm}^{3}$ and viral load of 11,000 copies $/ \mathrm{mm}^{3}$. Negative VDRL. Radiography with varied alterations in small and large articulations, decreased articular spaces and formation of osteophytes. Computerized tomography (CT) revealed sclerosis, cortical irregularity, marginal osteophytes in the sacroiliac joints and bilateral acetabular cortical irregularity. Normal bone densitometry. Reactive Protein C: 12. Negative serology for Chlamydia trachomatis IgG and IgM. Rheumatoid factor negative. HLA B27 anti- gen search negative. Ophthalmological examination normal, ruling out uveitis. Histopathology compatible with psoriasis. Conduct: MTX suspended and acitretin introduced at the dosage of $30 \mathrm{mg} / \mathrm{day}$, associated with antiretroviral therapy (zidovudine, lamivudine, lopinavir and ritonavir). Progression: After 60 days of treatment, new lesions appeared on the trunk, nail lesions worsened, with onychodystrophy, onycholysis and "oil stains" on all 20 nails, with great exacerbation of the articular picture, severe arthritis of large and small articulations, in addition to pain that was refractory to powerful analgesia, making it impossible to walk and perform simple daily tasks (Figure 2). At this time, PASI was 29. This clinical recrudescence determined the introduction of etanercept, at an induction dose of $50 \mathrm{mg} 2 \mathrm{x}$ per week, with a maintenance dose of $50 \mathrm{mg}$ per week. After 60 days of treatment, there was significant improvement of the cutaneous-articular symptom complex, with a PASI of 6.9 (Figure 3). The patient continues to be monitored through dermatology and infectology, using antiretrovirals and etanercept, without skin lesions and with significant improvement of the articular symptoms.

\section{DISCUSSION}

Since the beginning of the AIDS epidemic, a worsening of psoriasis progression is observed in patients with HIV infection, with sudden exacerbation of the clinical picture, onset of extensive cutaneous lesions, ungual and palmo-plantar expressive involvement, in addition to more aggressive articular affec-
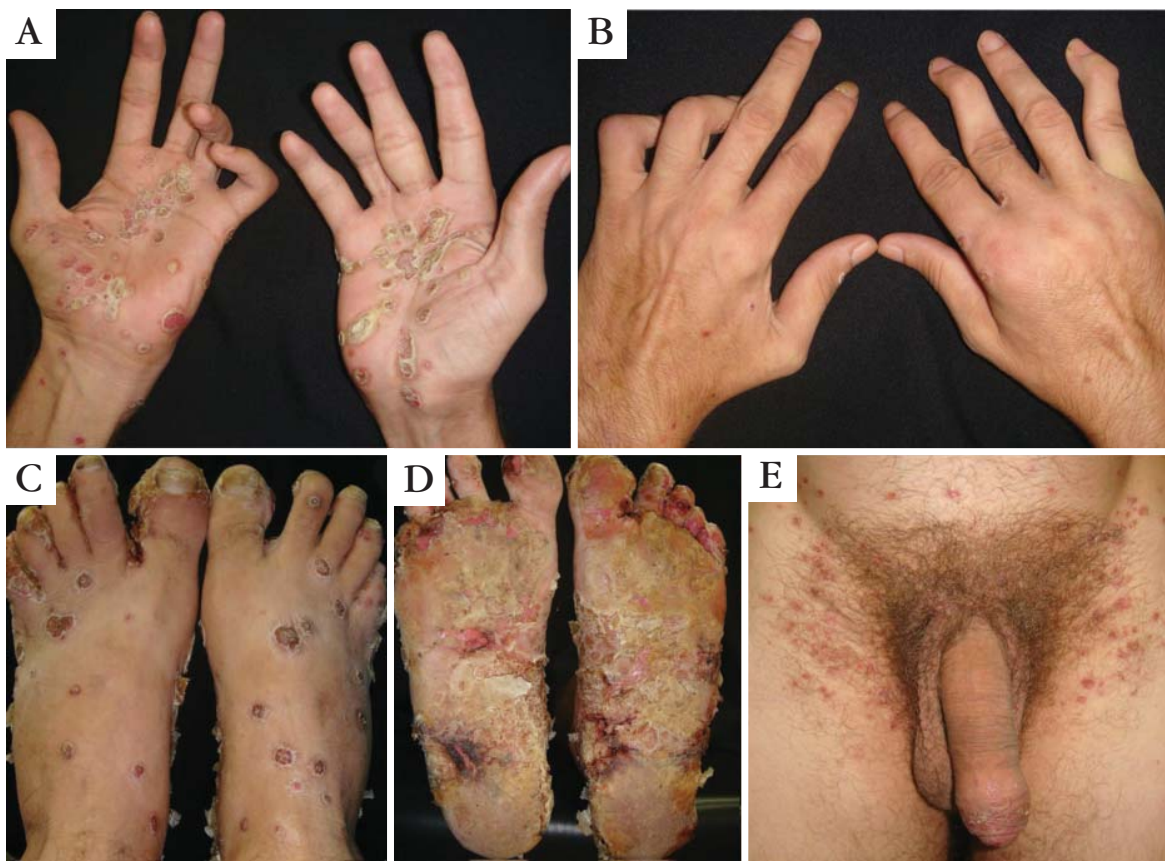

FIGURE 1: Erythematous-squamous plaques, some of them with crusts and fissures, bilaterally and predominantly in the inguinal and palmo-plantar regions 

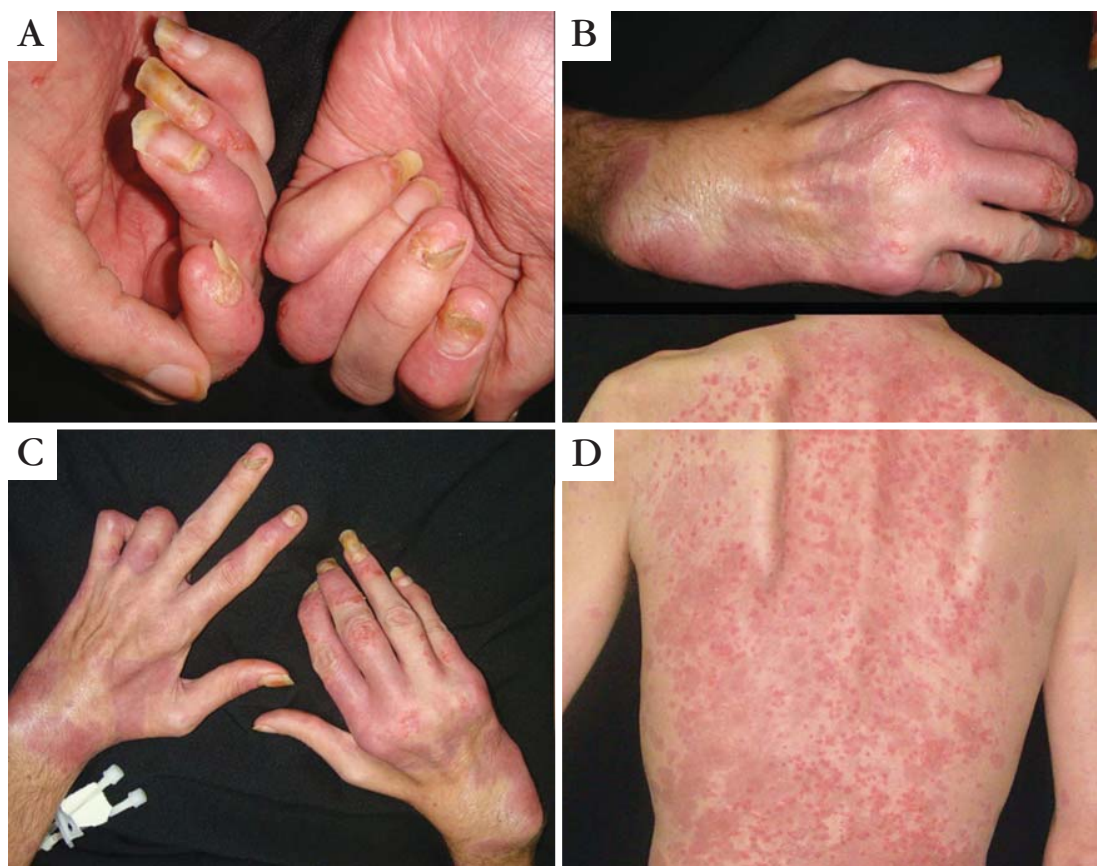

FIGURE 2: Onycholysis and onychodystrophy (A); arthritis of proximal and distal interphalangeal articulations of fingers, metacarpophalangeal and wrist articulations (B and C), papules and erythematous plaques with mild desquamation on the back (D)

tion, as occurred in the reported case. ${ }^{4}$ Some studies also suggest a relationship between immunosuppression progression and severity of psoriasis, above all with $\mathrm{T}-\mathrm{CD}^{+}$lymphocyte count below 400 cells/mm. ${ }^{5,6}$

The differential diagnosis of articular manifestations should be done with reactive arthritis, characterized by the presence of the triad polyarthritis, urethritis and conjunctivitis, accompanied by the typical skin lesions. It affects more often young men and is a characteristic of association with HLA-B27, which is present in around $80-90 \%$ of patients. ${ }^{7}$ In the case reported, the absence of urethritis and uveitis, as well as the negative results of the search for HLA B-27 and serology for Chlamydia trachomatis rule out the diagnosis.
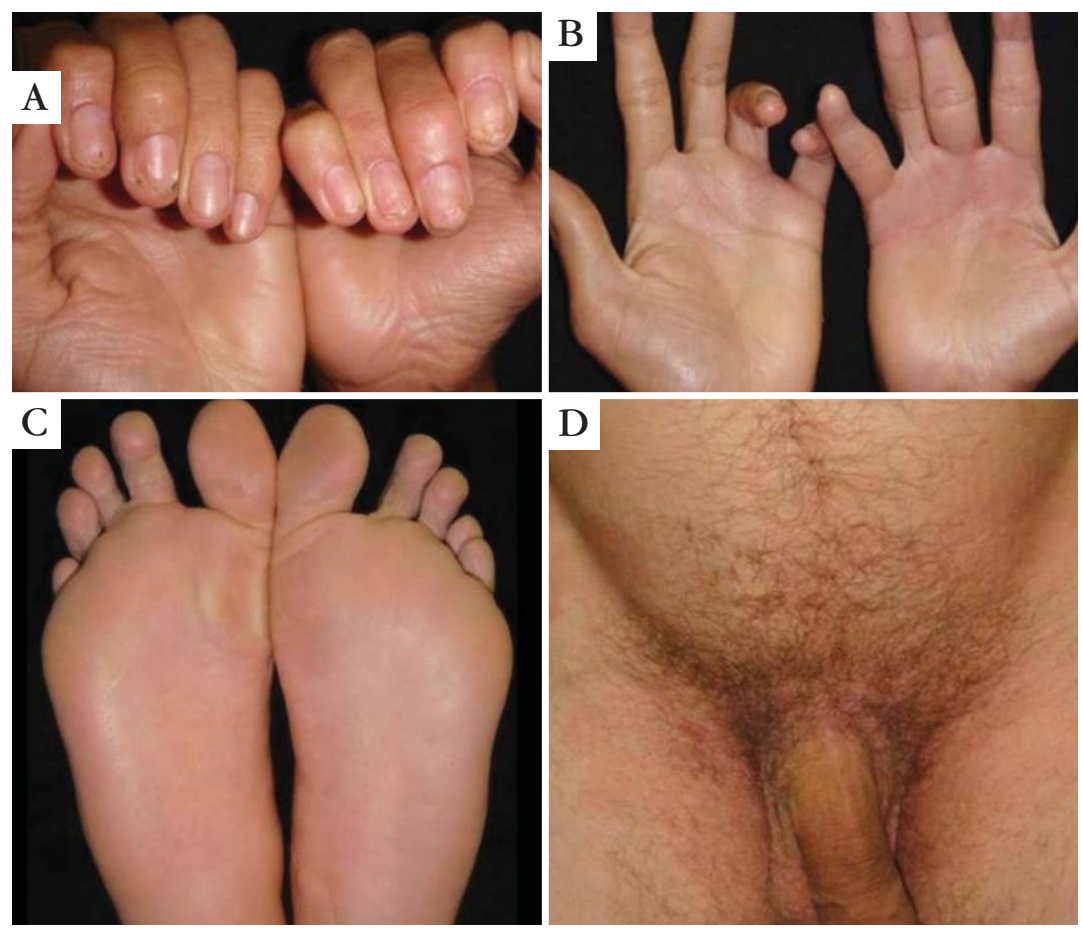

Figure 3: Clinical healing of skin lesions, with significant improvement of ungual and articular lesions 
As regards the treatment of cases of psoriasis exacerbated by HIV infection, many studies show that the introduction of antiretroviral therapy (ARVT), associated with conventional psoriasis treatments, improves the lesions and the quality of life of these patients $^{8}$. Other studies also mention that the interruption of ARVT may worsen the cutaneous-articular symptom complex. In some cases, however, the conventional treatments do not present such an adequate response, progressing to severe and incapacitating cutaneous-articular clinical pictures. During a long time biological agents were not recommended in these cases, for fear of increasing the risk of severe opportunistic infections ${ }^{9}$. Nevertheless, in the last few years, studies did not show evidence of significant increase in opportunistic infections with the use of biological medications for these patients, especially etanercept, indicated in severe psoriasis cases refractory to conventional therapy. However, serious clinical-laboratory control should be in place for early diagnosis of potential infectious complications, in addition to the adequate antiretroviral therapy. ${ }^{10,11,12}$

In the case reported, the indication of etanercept occurred as a result of the severe and incapacitating articular symptom complex, associated with recrudescence of skin lesions. The clinical improvement after introduction of etanercept was satisfactory, with the patient reaching PASI 90 within 60 days of treatment. The patient has been monitored for one year, with total remission of cutaneous lesions and substantial improvement of the articular involvement.

\section{REFERENCES}

1. Sociedade Brasileira de Dermatologia. Consenso Brasileiro de Psoríase. Rio de Janeiro: Sociedade Brasileira de Dermatologia; 2009. $116 p$

2. Romiti R. Novos Conceitos em psoríase. Rio de Janeiro: Elsevier, 2009.

3. Arruda L, Ypiranga S, Martins GA. Tratamento sistêmico da psoríase - Parte II: imunomoduladores biológicos. An Bras Dermatol. 2004:79:393-408.

4. Cuéllar ML, Espinoza LR. Rheumatic manifestations of HIV-AIDS. Baillieres Best Pract Res Clin Rheumatol. 2000;14:579-93.

5. Leal A, Ribera A, Daundén B. Psoriasis e infección por el virus de la inmunodeficiencia humana. Actas Dermosifiliogr. 2008;99:753-63.

6. Vano-Galvan S, Jaen P. Severe psoriasis due to cessation of antiretroviral therapy in a patient with human immunodeficiency virus. Isr Med Assoc J. 2008;10:557 558.

7. Taylor W, Gladman D, Helliwell P, Marchesoni A, Mease P, Mielants H, et al. Classification criteria for psoriatic arthritis. Development of new criteria from a large international study. Arthritis Rheum. 2006;54:2665-73.

8. Patel RV, Weinberg JM. Psoriasis in the patient with human immunodeficiency virus, Part2: Review of treatment. Cutis. 2008:82:202-10.

9. Hamilton CD. Infectious complications of treatment with biologic agents. Curr Opin Rheumatol. 2004:16:393-8.

10. Ting PT, Koo JY. Use of etanercept in human immunodeficiency virus (HIV) and acquired immunodeficiency syndrome (AIDS) patients. Int J Dermatol. 2006;45:689-92.
11. Wallis RS, Kyambadde P, Johnson JL, Horter L, Kittle R, Pohle M, et al. A study of the safety, immunology, virology, and microbiology of adjunctive etanercept in HIV1-associated tuberculosis. AIDS. 2004;18: 257-64.

12. Aboulafia DM, Bundow D, Wilske K, Ochs UI. Etanercept for the treatment of human immunodeficiency virus associated psoriatic arthritis. Mayo Clin Proc. 2000;75:1093-1098

How to cite this article/Como citar este artigo: Santos M, Rabelo R, Mendes L, Vilasboas V, Talhari C, Talhari S. Severe cutaneous and arthritic psoriasis in patient with Aids: a good outcome with therapy using etanercept. An Bras Dermatol. 2012;87(1):135-8. 